\title{
PENGARUH KOMPOSISI TIM UJI TRAMPIL DAN KEPUASAN KERJA TERHADAP KINERJA KOLATARMABAR
}

\author{
Darwin Sagala1
}

\begin{abstract}
The objective research is to obtain information concerning effect capability tester team composition and job satisfaction toward Job performance or outcomes Indonesian navy western fleet exercise command. The research was conducted by using survey method with path analysis in testing hypothesis. In this research 90 from 100 personel Indonesian navy western fleet exercise command selected random sampling. The research was focused on three aspect: composition team and job satisfaction toward outcomes. The data were collected with questionare and analyzed with path analysis result on the analysis it is calculated that (1) there the positive direct effect of team composition toward job satisfaction (2) there is the positive job satisfaction toward outcomes (3) there is positive direct effect of team composition toward outcomes.
\end{abstract}

Keywords: team composition,job satisfaction and outcomes.

\section{PENDAHULUAN}

Indonesia sebagai Negara kepulauan memiliki 17.499 pulau serta panjang garis pantai $\pm 80791 \mathrm{~km}$. Untuk mengamankan wilayah laut Yurisdiksi yang sedemkian luas Indonesia, membutuhkan kesiapan tempur Kapal-kapal perang milik TNI AL. Kesiapan tempur sebuah Kapal perang (KRI) menjadi syarat kelaikan, untuk melaksanakan operasi penindakan terhadap kapal yang melanggar kedaulatan, kegiatan illegal di laut seperti: Illegal migrant, illegal Fishing, illegal logging, illegal mining, Drug trafficking, Weapon traficking dan lain sebagainya.

Kelaikan KRI yang akan dioperasikan, diharuskan memiliki kemampuan sesuai filosofi tempur dari masing-masing jenis kapal, antara lain: harus memiliki kemampuan untuk melaksanakan patroli pengamanan wilayah laut dari ancaman militer ataupun ancaman yang bersifat non militer. Kapal yang siap operasi minimal sudah lulus uji trampil L-1 dan L-2 oleh Komando dan Latihan Armada.

Beberapa kejadian kecelakaan laut yang dialami KRI seperti: kejadian terbaliknya KRI Teluk Peleng di perairan Tanjung Priok tahun 2013, tabrakan KRI Nusanive dengan KM. Ngapulu di perairan Jayapura tahun 2015, menimbulkan pertanyaan: apakah kapal-kapal yang sedang dioperasikan sudah melalui uji trampil L-1 dan L-2? (L-1 adalah menilai dan mengevaluasi ketrampilan ABK KRI dalam menempati posisi dan penguasan tugas dan tanggung jawab pada setiap peran dan dilaksanakan pada saat di dermaga sedangkan L-2 adalah menilai dan mengevaluasi ketrampilan ABK KRI dalam menempati posisi dan penguasan tugas dan tanggungjawab dilaksanakan sambil berlayar).

TNI Angkatan Laut memiliki dua Komando Latihan yaitu: Komando Latihan armada R.I Kawasan Timur disingkat dengan nama Kolatarmatim yang

\footnotetext{
${ }^{1}$ Peneliti berdinas di Kementerian Pertahanan di Jalan Merdeka Barat Jakarta.
} 
bertanggungjawab menguji kapal perang yang berpangkalan di Wilayah timur yaitu di Surabaya, kemudian yang satu lagi, adalah Komando Latihan Armada R.I Kawasan Barat disingkat dengan nama Kolatarmabar, yang bertanggung jawab menguji kapal perang yang berpangkalan di wilayah barat berada di Jakarta. (SKEP KASAL NO.Skep/156/II/2009 tgl 12 Februari 2009)

\section{Kinerja}

Menurut James L. Gibson (2012:374) "job performance is the outcomes of jobs relate to the purpose of the organization such a quality, efficiency and other criteria of effectiveness. Kinerja adalah Hasil kerja sesuai dengan harapan organisasi seperti kualitas, efisiensi dan kriteria dari efektifitas.

Demikian halnya dengan Jason A. Colquit. J. LePine dan Michael J. Weson (2015:235)," job performance is formally defined as the value of the set of employee behaviors that contribute, either positively or negatively to organizational goal accomplish" Bahwa kinerja didefinisikan sebagai nilai dari perilaku para karyawan dalam berkontribusi secara positif atau negatif untuk mencapai tujuan organisasi.

Menurut John R. Schermerhon (2005:238) "job performance is measured as quantity of task accomplished by In dividual or Group." Kinerja adalah Kuantititas dari tugas yang diselesaikan oleh individu maupun kelompok.

Dari pendapat para ahli di atas maka dapat disintesakan bahwa kinerja adalah akumulasi hasil kerja akhir individual atau kelompok yang dihasilkan dari sejumlah keahlian atau kompetensi yang dimiliki tim, bekerja sesuai prosedur, bekerja sesuai waktu, bekerja sesuai tugas tim untuk mencapai kinerja organisasi, dengan indikator: bekerja sesuai prosedur, bekerja sesuai waktu, bekerja sesuai fungsi azasi kapal dan bekerja sesuai tujuan organisasi.

\section{Komposisi Tim}

Menurut Stephen, P. Robbins (2013:309), dalam bukunya Perilaku Organisasi dikatakan bahwa kelompok kerja yang lebih sukses dari kelompok lain disebabkan variable-variabel seperti kemampuan anggota kelompok, ukuran kelompok, tingkat konflik dan tekanan internal pada anggota untuk menyesuaikan diri pada norma kelompok.

Komposisi tim menurut Anit Somech dan Anat Drach Zahavy dalam tulisannya mengatakan bahwa Komposisi tim adalah konfigurasi berbagai macam keahlian di dalam satu tim yang berpengaruh dalam kekuatan tim dalam proses tim dan kinerja.

"Team composition is the configuration of member attributes in a team and is thought to have a powerful influence on team process and outcomes" Komposisi tim adalah konfigurasi dari atribut anggota di dalam satu tim yang memiliki pengaruh kuat dalam proses dan hasil kerja.

Menurut Conquitt (2010:234) bahwa kekuatan tim tidak terlepas dari Peran anggota tim, Kemampuan anggota, Kepribadian anggota, keberagaman anggota dan besarnya tim,dalam bukunya dikemukakan bahwa ada lima aspek dalam menyusun komposisi tim yakni," teams are group of two or more people who interact and influence each other,are mutually accountable for achieving common goals associated withorganizational objectives and perceive themselves as a social entity within an organization."

Tim adalah gabungan dari dua orang atau lebih yang saling berinteraksi dan mempengaruhi satu sama lain, memiliki tanggungjawab bersama untuk mewujudkan tujuan organisasi dan keinginan mereka sebagai bagian dari organisasi. 
Dari pendapat ahli di atas dapat disintesiskan bahwa komposisi tim adalah tim kerja yang berisikan personel yang efektif, terdiri dari besaran tim sesuai bidang tugas, memiliki kompetensi, memiliki pengalaman penugasan, memiliki semangat menyelesaikan tugas tim, sesuai tujuan organisasi dengan indikator besaran tim, memiliki kompetensi, pengalaman penugasan dan memiliki semangat, menyelesaikan tugas tim.

\section{Kepuasan Kerja}

Job Satisfaction menurut Colquitt (2005:98)"represent how you feel about your job and what you think about your job." Representasi bagaimana anda merasakan tentang pekerjaan dan bagaimana anda berpikir tentang pekerjaan anda.

Jennifer M.George dan Gareth T. Jones (2015:76) mengatakan bahwa: "what causes different employees to be satisfied or dissatisfied with their job? Four Factor affect the level of job satisfaction a person experiences: personality, Values, the work situation and social influence". Bahwa berbeda-beda penyebab kepuasan dan tidak puas karyawan tentang pekerjaannya, ada empat faktor yang menyebabkan tingkatan kepuasan antara lain : personalitas, nilai, situasi kerja dan pengaruh sosial.

Dari pendapat ahli di atas maka dapat disintesiskan bahwa Kepuasan kerja adalah respon perasaan senang atau tidak menyenangkan individu terhadap pekerjaannya, tanggung jawabnya, rekan kerja, promosi dan perasaan terhadap reward yang diterima dari organisasi tempat bekerja, dengan indikator respon perasaan terhadap pekerjaannya, respon perasaan terhadap rekan kerja, respon perasaan terhadap lingkungan dan respon perasaan terhadap reward dari organisasi.

\section{METODE}

Metode peneltian yang digunakan pada penelitian ini adalah metode survey, dengan pendekatan kuantitatif. Penelitian ini dilakukan di Kolatarmabar dan penelitian ini sebanyak 82 orang dengan sampel sebanyak 20 orang. Pengambilan sampel menggunakan teknik simple random sampling.

Penelitian ini menggunakan analisis jalur (path analysis) untuk mengetahui adanya pengaruh antar variabel sesuai dengan model kausal yang terbentuk. Sebelum kuesioner digunakan dalam penelitian ini, terlebih dahulu dilakukan uji coba untuk menentukan validitas dan reliabilitas instrumen. Hasil tersebut digunakan sebagai instrumen untuk mengambil data penelitian di lapangan. Analisis data meliputi: 1) deskripsi data, 2) uji prasyarat analisis normalitas, 3) analisis jalur yang meliputi: analisis model, pengujian hipotesis dan penentuan tingkat pengaruh. 


\section{Pembahasan Hasil Penelitian}

\section{Pengaruh Komposisi Timterhadap Kinerja}

Dari hasil pengujian hipotesis pertama dapat disimpulkan bahwa terdapat pengaruh langsung positif komposisi tim terhadap kinerja dengan nilai koefisien korelasi sebesar 0,455 dan nilai koefisien jalur sebesar 0,340. Ini memberikan makna komposisi tim berpengaruh langsung terhadap kinerja.

Hasil penelitian ini senada dengan pendapat beberapa ahli di antaranya Menurut Gibson et.al (2010:174) kenapa sebuah tim dibentuk:There is no simple explanation for the increased usage of team in organization form team, including enhanced productivity, flattening of organization, need for flexibility and quiker decision, workforce diversity, improved quality and increased customer satisfaction.

Banyak penjelasan kenapa sebuah tim dibentuk dalam organisasi, antara lain untuk : menambah produkvitas, menggerakkan organisasi, untuk fleksibilitas, kemampuan kerja yang beragam,meningkatkan kualitas serta menambah kepuasan pelanggan.

Demikian halnya komposisi tim menurut Anit Somech dan Anat Drach Zahavy dalam tulisannya mengatakan bahwa: komposisi tim adalah konfigurasi berbagai macam keahlian didalam satu tim yang berpengaruh dalam kekuatan tim dalam proses tim dan kinerja.

"Team composition is the configuration of member attributes in a team an is thought to have a powerful influence on team process and outcomes" Komposisi tim adalah konfigurasi berbagai macam keahlian didalam satu tim yang berpengaruh dalam kekuatan tim dalam proses tim dan kinerja.

Menurut Schermerhorn (2004:181) et.al mengatakan mendapatkan komposisi tim pengaruhnya terhadap kinerja : In the sport world coaches and managers spend a lot of time at the start of each season to join new members with old ones and form a strong team, yet we all know that even the most experienced team can run into problem as a season progresses, Members slack off become disgruntled with another;... when these thing happen, concerned owners, managers, and players are apt to examine their problem, take corrective action to rebuild the team, and restore the teamwork needed to Achieve high performance.

Dalam bidang melatih dan mengendalikan dalam bidang dunia olahraga, menghabiskan banyak waktu, dimulai dari setiap awal musim, menggabungkan anggota lama dan membentuk tim yang kuat, seperti yang kita ketahui banyak ditemukan masalah seperti berselisih hingga menjadi bersungut-sungut satu sama lain...ketika hal ini terjadi harus menjadi perhatian pemilik, manajer dan pemain untuk menyelesaikan masalah, mengambil langkah koreksi untuk membangun tim dan membentuk ulang komposisi tim yang dibutuhkan untuk kinerja yang hebat.

Menurut J. Richard Hackman tentang kinerja yang hebat dipengaruhi oleh komposisi tim, beliau mengatakan sebagai berikut: Members of high performance team have the right mix of skills, including technical skill, problem solving, decision making and interpersonal skills. A high performance team has strong core values that help guide team member's attitudes and behaviors in direction consistent with the team purpose

Anggota dari tim yang memiliki kinerja hebat harus dari komposisi yang tepat dari berbagai ketrampilan termasuk kemampuan teknis, penyelesaian masalah, mengambil keputusan, kemampuan interpersonal. Kinerja tim yang hebat memiliki nilai dasar antara lain, memiliki sikap menolong sesama tm dan perilaku konsistensi terhadap tugas tim.

Dengan demikian komposisi tim berpengaruh langsung positif terhadap kinerja. 


\section{Pengaruh Kepuasan Kerja terhadap Kinerja}

Dari hasil pengujian hipotesis kedua dapat disimpukan bahwa terdapat pengaruh langsung positif kepuasan kerja terhadap kinerja dengan nilai koefisien korelasi sebesar 0,456 dan nilai koefisien jalur sebesar 0,342. Ini memberikan makna kepuasan kerja berpengaruh langsung terhadap kinerja.

Hasil penelitian ini senada dengan pendapat beberapa ahli di antaranya Stephen Bushardt, Robert. E Schnake (57) memberikan contoh, apabila kepuasan kerja karyawan dalam bentuk need adalah uang maka pencapaian akan uang akan berpengaruh terhadap kinerja karyawan tersebut: While money is one of the most powerful motivational tools, its use must be tailored to each employee's value. These authors suggest that for money to motivate, three consideration must be met. One, the employee must have a high "net"preference for money. This concept of "Net" is important because frequently long hours are part of higher pay. The positive motivating effect of more pay must be greater than the negative effects of unsiderable hours.Second, there needs to be direct relationship between money and performance that the employee can perceive. third, there need to be direct relationship between effort and performance. If effort increases, performance should be increase.

Ketika uang menjadi yang sesuatu yang paling bernilai dan menjadi alat motivasi bagi para karyawan, maka hal ini harus diingatkan kepada masing-masing karyawan. Para penulis menyarankan, apabila uang menjadi motif maka ada tiga pertimbangan, seperti kinerja karyawan harus hebat karena sebagai referensi untuk mendapatkan uang. Konsep tentang penghasilan sangat penting, karena frekuensi lamanya bekerja merupakan bagian dari penghitungan penghasilan, hal ini lebih berpengaruh positif dibandingkan negatifnya. Kedua need harus ada kaitan langsung antara uang dan kinerja seperti para yang karyawan harapkan. Ketiga need harus berkaitan langsung antara upaya dan kinerja. Apabila upaya meningkat maka kinerja akan meningkat.

Menurut Mc.Shane (110) hubungan antara Job Satisfaction dan Performance: Is happy worker a more productive worker, and most corporate leaders likely think so. Now Organizational Behavior believe that; there is a moderately positive relationship between job satisfaction and performance. In other words, workers tend to be more productive to some extent when they have more positive attitudes towards their job and work places.

Kebanyakan pemimpin perusahaan yakin bahwa, pekerja yang gembira akan menjadi pekerja yang lebih produktif, Saat ini dalam perilaku organisasi di yakini bahwa, ada pengaruh yang kuat antara kepuasan kerja dan kinerja. Dengan kata lain bahwa pekerja yang puas dalam pekerjaannya akan memiliki sikap yang positif pada saat menghadapi pekerjaannya dan pada tempatnya bekerja.

kinerja.

Dengan demikian terdapat pengaruh langsung positif kepuasan kerja terhadap 


\section{Pengaruh Komposisi Tim terhadap Kepuasan Kerja}

Dari hasil pengujian hipotesis ketiga dapat disimpulkan bahwa terdapat pengaruh langsung positif komposisi tim terhadap kepuasan kerja dengan nilai koefisien korelasi sebesar 0,335 dan nilai koefisien jalur sebesar 0,335. Ini memberikan makna komposisi tim berpengaruh langsung terhadap kepuasan kerja.

Hasil penelitian ini senada dengan pendapat beberapa ahli di antaranya Menurut Gibson et.al, (2012:232) individu bergabung dalam satu kelompok karena bermacam alasan:"formal and informal groups form various reasons. Some reason involve need, proximity, attraction, goals, and economics. The satisfaction need : security, social, esteem"

Menurut Don Hellriegel dan John W. Slocum, jr (2010:230) mengatakan: "a team is small number of employees with complementary competencies who are committed to common performance goals and working relationships for which they hold themselves mutually accountable."

Sebuah tim adalah kumpulan sejumlah kecil karyawan dengan masing-masing kompetensi yang sepakat untuk mencapai tujuan utama dan bekerjasama untuk tanggungjawab bersama

Menurut Conquitt (2009:365) bahwa ada lima aspek yang perlu didalam membangun tim antara lain : "member roles, member ability, member personality, member diversity,team size" peran anggota, kemampuan anggota, kepribadian anggota, keragaman anggota, besaran tim. Sehingga individu yang menjadi anggota tim harus mampu mengalahkan ego individu tetapi lebih kepada pencapaian tujuan organisasi

Job Satisfaction menurut Colquitt (2009: 98) "represent how you feel about your job and what you think about your job." Representasi bagaimana anda merasakan tentang pekerjaan dan bagaimana anda berpikir tentang pekerjaan anda.

Bahwa berbeda-beda penyebab kepuasan dan tidak puas karyawan tentang pekerjaannya, ada empat faktor yang menyebabkan tingkatan kepuasan antara lain : personalitas, nilai, situasi kerja dan pengaruh sosial.

Dengan demikian komposisi tim berpengaruh langsung positif terhadap kepuasan kerja.

\section{PENUTUP}

Kesimpulan: Berdasarkan hasil penelitian dan pembahasan yang dikemukakan sebelumnya, dapat disimpulkan sebagai berikut :

Pertama : Komposisi tim berpengaruh langsung positif terhadap Kepuasan kerja,artinya penentuan personel tim yang tepat mengakibatkan kepada Kepuasan kerja Tim Uji trampil Kolatarmabar.

Kedua : Kepuasan kerja berpengaruh langsung positif terhadap Kinerja Tim artinya Kepuasan kerja yang dirasakan oleh Personel Tim uji Kolatarmabar mengakibatkan peningkatan Kinerja Kolatarmabar.

Ketiga : Komposisi tim berpengaruh langsung positif terhadap kinerja .Artinya komposisi tim yang tepat sesuai bidang tugas yang akan dikerjakan mengakibatkan Peningkatan kinerja Kolatarambar.

Saran: Berdasarkan hasil penelitian yang dikemukakan diatas dapat diajukan saransaran praktis untuk perbaikan komposisi tim dan kepuasan kerja agar dapat mendorong peningkatan kinerja Kolataramabar sebagai berikut :

Pertama,saran untuk Komandan Kolatarmabar sebagai pimpinan seluruh tim uji trampil agar selalu membangun keterkaitan dan keterikatan antar tim sehingga tercipta sinergitas yang baik antar anggota tim dengan anggota tim lainnya,hal ini akan 
membuat pelaksanaan uji trampil merasa nyaman dalam karir baik jabatan maupun pangkat.

Kedua Komandan Kolatarmabar : 1). agar senantiasa meningkatkan kemampuan anggota tim melalui pendidikan atau pelatihan baik terkait didalam negeri maupun keluar negeri dihadapkan kepada kemajuan teknologi yang dimiliki oleh KRI yang baru dibeli TNI AL dan mengajukan permintaan personel-personel yang memiliki kompetensi dan semangat serta berprestasi ke satuan atas untuk ditempatkan di Kolatarmabar sehingga meningkatkan rasa bangga atau prestise bagi para prajurit TNI $\mathrm{AL}$, apabila ditempatkan untuk mengawaki Kolatarmabar.

\section{DAFTAR RUJUKAN}

Bryson, Jhon M. Perencanaan Strategis bagi organisasi social. Pustaka Pelajar. 2003

Colquit et.al Organizational Behavior Improving Performance and commitment in the workplace. New York: Mc.Graw Hill. 2009.

David, Fred. Strategic management, manajemen strategis. konsep edisi 10, Penerbit Salemba Empat.

Djiwandono, Sri Esti Wuryani. Psikologi Pendidikan. Jakarta: penerbit PT.Gramedia Widiasarana Indonesia, 2006.

Draft, Richard L.New Era of Managemen, Tenth Edition. South Western Cengage Learning, 2010

Gareth Jones, Organizational Theory, Design and Change, Sixth Edition, Pearson

Gibson, Donnelly, Organizations Behavior, structure, Processes, Mc.Graw-Hill International Edition

Hersey, Paul., Kenneth H.Blanchard,Dewey E.Jhonson, Management of Organizational Behavior, Utilizing human Resource, International Edition, Seventh Edition, Prentice hall International,Inc.

Ivancevich, Konopaske, Mattesson, Organizational Behavior and managemen. Eight Edition, Mc.Graw Hill International Edition

Jones, George. Understanding and managing Organizational Behavior, Merrill is an impirint of Pearson

Kinicki, Kreitner. Organizational Behavior, Mc.Graw-Hill International Edition 
Kydd, Lesley. Megan Crawford, Colin Riches, Professional development for Education Management, Pengembangan Profesional untuk manajemen pendidikan, PT.grasindo

Luthans, Fred. Organizational Behavior, Mc.Graw Hill International 2008.

Moeheriono, Pengukuran Kinerja berbasisi Kompetensi edisi revisi,PT.Raja Grafindo Persada, Jakarta

Olsen, Erica.Strategic Planning Kit for Dummies,Second Edition,John Wiley \& Sons,Inc

Robbins, Stephen P.Organizational behaviors. New Jersey; Pearson Prentice Hall 2009)

Rohman, Muhammad. Manajemen pendidikan,Analisis dan Solusi terhadap Kinerja Manajemen kelas dan Strategi Pengajaran. Prestasi Pustaka Publisher.

Schermerhorn, Hunt, Osborn, UHL-Bien,Organizational Behavior,International Student Edition.

Somech, Anit -Anat Drach Zahvy in journal of Management Vol.39, No.3 March 2013, Translating team creativity to innovation implementation the role of team composition and climate for innovation. 